\title{
Clinical profiles and outcomes of acute ST-segment elevation myocardial infarction in young adults in a tertiary care center in Saudi Arabia
}

Haitham Sakr, MD, FRCP, Ahmed S. Azazy, MD, MSc, Ali Hillani, MD, Mohamed Ebada, MD, MSc, Abdulrahman Alharbi, MD, Saleh Alshalash, MD, FRCPC, Rami Abazid, MD, FSCCT, Abdulrahman Algassim, MD, MSc.

\begin{abstract}
الأهداف : دراسة الخصائص السريرية والنتائج للشباب الذين يعانون من احتشاء



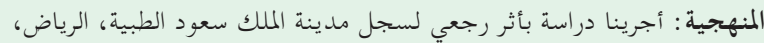

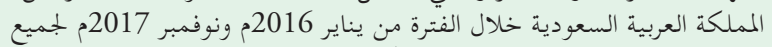

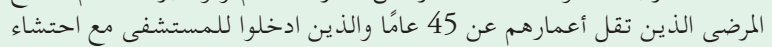




الفترة.

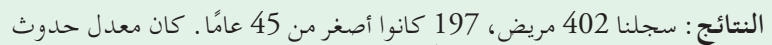

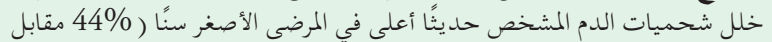

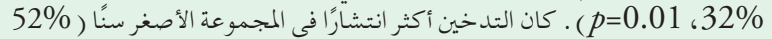

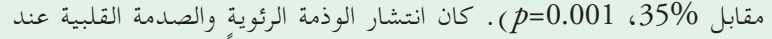

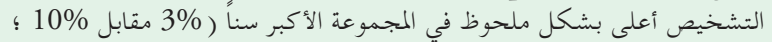

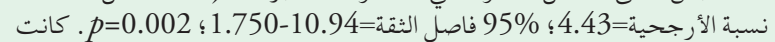

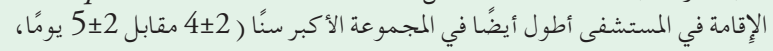
. $p=0.03$



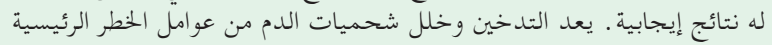

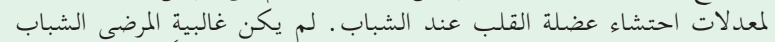

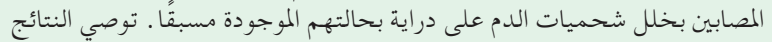


الشباب وتعزيز برامج الوقاية من التدخين.
\end{abstract}

Objectives: To investigate the clinical profiles and outcomes of young adults presenting with ST-segment elevation myocardial infarction (STEMI).

Methods: We retrospectively reviewed King Saud Medical City, Riyadh, Saudi Arabia, registry between January 2016 and November 2017 for all patients younger than 45 years old who were admitted with STEMI. We compared this study population to a control group of patients aged 45 years and older who were enrolled in the same period.

Results: In total, 402 patients were enrolled; 197 were younger than 45 years. The incidence of newly diagnosed dyslipidemia was higher in younger patients (44\% vs. $32 \%, p=0.01$ ). Smoking was significantly more prevalent in the younger group $(52 \%$ vs. $35 \%, p=0.001)$. The prevalence of pulmonary edema and cardiogenic shock on presentation was significantly higher in the older group (3\% vs. 10 ; odds ratio, $4.43 ; 95 \%$ confidence interval, $1.750-10.94 ; p=0.002)$. Hospital stay was also longer in the older group ( $4 \pm 2$ vs. $5 \pm 2$ days, $p=0.03$ ).

Conclusion: ST-segment elevation myocardial infarction in young patients has a favorable outcome. Smoking and dyslipidemia are the main risk factors for STEMI in young individuals. The majority of young patients with dyslipidemia were not aware of their pre-existing condition. Our findings recommend local adaptation and implementation of screening programs for dyslipidemia in the young and the reinforcement of smoking prevention programs.

Keywords: ST elevation myocardial infarction, dyslipidemias, smoking, young adult, Saudi Arabia

$$
\text { Saudi Med J 2021; Vol. } 42 \text { (11): 1201-1208 }
$$$$
\text { doi: 10.15537/smj.2021.42.11.20210412 }
$$

From the Department of Cardiology (Sakr, Azazy, Hillani, Ebada, Alharbi, Algassim) King Saud Medical City; from the Department of Medicine (Algassim), King Saud Medical City; from the Department of Cardiology (Sakr), King Abdullah Bin Abdulaziz University Hospital; from the Department of Cardiology (Alshalash), King Fahad Medical City; form the Department of Medicine (Algassim), Prince Sultan Military Medical City, Riyadh, Kingdom of Saudi Arabia; from the Department of Cardiology (Hillani), University of Montreal Hospital Center, Montreal, Quebec; and from the Division of Nuclear Medicine (Abazid), London Health Sciences Centre, University Hospital, London, Ontario, Canada.

Received 13th June 2021. Accepted 28th September 2021.

Address correspondence and reprint request to: Dr. Abdulrahman Algassim, Department of Cardiology, King Saud Medical City, Riyadh, Kingdom of Saudi Arabia. E-mail: a.algassim@ksmc.med.sa ORCID ID: https://orcid.org/0000-0001-7834-520X 
T-segment myocardial infarction (STEMI), a serious $\checkmark$ consequence of coronary artery disease (CAD), tends to affect people between the sixth and seventh decade of life. ${ }^{1}$ Patients younger than 45 years of age represent approximately $5-10 \%$ of all acute myocardial infarction (AMI) cases., ${ }^{2,3}$ In developing countries, however, AMI frequently occurs at a younger age, approximately one decade earlier than that reported in developed countries. ${ }^{4}$ The Middle East has one of the highest percentages $(11 \%)$ of adults who develop STEMI for the first time before the age of 40 years. ${ }^{5}$ In comparison, the rate in North America is $4 \%$, Western Europe is $2.7 \%$, and Africa is $9.7 \%{ }^{6}$

In young patients, STEMI has lower mortality rates and a lower incidence of related major adverse cardiovascular events (MACE), such as cardiogenic shock or stroke. Moreover, a higher rate of successful primary percutaneous coronary intervention accompanied by higher thrombolysis in myocardial infarction grade flow and fewer bleeding complications have been reported in young patients. ${ }^{7}$

The mechanisms and disease courses of STEMI in young individuals may differ from those in the elderly. Cigarette smoking with or without cocaine abuse is considered one of the strongest risk factors associated with CAD in young adult., ${ }^{2,3}$ Moreover, a family history of premature coronary artery disease is frequently encountered as an important risk factor in youth. ${ }^{8}$ This could be attributed to genetic disorders related to lipid metabolism. ${ }^{9}$ Most previous reports have shown favorable outcomes in young adults with AMI. ${ }^{10}$ However, identifying the variations of such risk factors for STEMI in the younger age group might have an important value for preventive measures and treatment plans.

In Riyadh, Saudi Arabia, there are 8 million residents, of which 6.5 million are younger than 45 years. ${ }^{11}$ This is partly due to the presence of predominantly male young migrant workers, representing more than 3 million residents. ${ }^{12}$ To date, several studies have investigated AMI in patients younger than 45 years. ${ }^{1,2,13}$ However, only few have focused on STEMI. ${ }^{7}$ Locally, approximately $25 \%$ of patients presenting with STEMI are younger than 45 years. ${ }^{14}$ However, local studies investigating such cases are extremely scarce. ${ }^{5,15} \mathrm{On}$ the same note, specific modifiable risk factors such as

Disclosure. Authors have no conflict of interests, and the work was not supported or funded by any drug company. smoking (21\%), obesity (37\%), and diabetes (23\%) are more prevalent regionally than globally. ${ }^{16-18}$ Therefore, the circumstances were ideal for investigating the clinical profile and outcome of acute STEMI in adults younger than 45 years in comparison to those of older patients.

Methods. We retrospectively reviewed our electronic database, Medysis ${ }^{\circledast}$ (Riyadh, Saudi Arabia), of all patients younger than 45 years of age who were admitted with a confirmed diagnosis of STEMI between January 2016 and November 2017 at a tertiary care hospital, King Saud Medical City (KSMC), Riyadh, Saudi Arabia. We compared the study population to a control group of older patients consecutively enrolled in a contemporary period. In each subject, we reported the presence of traditional cardiovascular risk factors, including current smoking habits and a family history of $\mathrm{CAD}$, dyslipidemia, arterial hypertension, and diabetes mellitus. In addition, clinical and laboratory data including blood pressure, laboratory tests, electrocardiography (ECG), weight, height, body mass index, echocardiography, in-hospital outcomes (recurrent chest pain, heart failure, stroke, bleeding, cardiogenic shock, and death), length of hospital stay, and circadian dependence of symptom onset were recorded. This study was approved by the Institutional Review Boards of KSMC, which waived the requirement for patient consent.

Inclusion criteria were all patients aged $<45$ years, diagnosed with STEMI based on clinical presentation, with available ECG and blood tests (creatine kinase and troponin levels were included). The ECG criteria used to diagnose STEMI were any new ST-segment elevation measuring $>0.2 \mathrm{mV}$ in $\geq 2$ contiguous leads (V1-V3) or $>0.1 \mathrm{mV}$ in all other leads, or the presence of a new left bundle branch block accompanied by an increase in troponin-I or T. We excluded all patients with incomplete data, those with a non-confirmed diagnosis of STEMI.

Data was retrospectively collected from clinical records and electronic charts, web-based clinical databases, and clinical imaging storage systems. The web-based clinical databases contain the following information: demographic data, cardiovascular risk factors, and clinical and laboratory data, as well as the time of symptom onset subdivided into 4 categories (midnight-06:00, 06:00-12:00, 12:00-18:00, and 18:00-24:00). Echocardiographic variables, including left ventricular (LV) ejection fraction, LV dimensions, and diastolic function, were recorded.

We looked at treatment strategy, thrombolytic therapy (alteplase) vs. invasive treatment. Major adverse cardiovascular events were defined as a composite of 
cardiac death, stroke, and acute kidney injury. Cardiac death was defined as death due to pump failure, cardiogenic shock, arrhythmia, or severe pulmonary edema.

Statistical analysis. The collected quantitative data was described in terms of mean \pm standard deviation and range, and the qualitative data was described in terms of frequency and percentage. Comparisons between young and old patients were carried out using the Mann-Whitney test, the test of proportion $(Z)$, the Chi-square test $\left(x^{2}\right)$, or the Fisher exact test as appropriate. Statistical significance was set at $p<0.05$. Statistical analyses and data plotting were performed using GraphPad Prism 8.

Results. We included 402 patients, of whom 197 (49\%) were younger than 45 years. The baseline characteristics are shown in (Table 1). The mean age was $40 \pm 4$ years among patients younger than 45 years and $55 \pm 7$ years among those older than 45 . Women represented $2.5 \%$ of the young group and $3 \%$ of the elderly group. Patients with a history of hypertension ( $25 \%$ vs. $36 \%$ ), diabetes ( $40 \%$ vs. $52 \%$ ), dyslipidemia ( $16 \%$ vs. $24 \%)$, and obesity (7\% vs. $19 \%)$ were significantly less common among the younger group than among the older group. However, upon further workup, the incidence of newly diagnosed dyslipidemia was found to be more common in the younger age group (44\% vs. 32\%). There was no significant difference in the overall prevalence of dyslipidemia between the younger and older groups (60\% vs. 56\%). Furthermore, smoking history was significantly more prevalent in the younger group ( $52 \%$ vs. $35 \%$ ), as was the case with substance abuse (3\% vs. $0.5 \%$ ). Importantly, a history of prior myocardial infarction was significantly more frequent in elderly patients than in younger patients (12\% vs. $6 \%)$.

The atypical symptomatic presentation and diurnal variation did not show any significant difference between the groups, and oxygen saturation was higher in the younger group ( $97 \%$ vs. $96 \%$; Table 2 ). Symptom to door time of $<12$ hours was more common in younger patients $(81 \%)$ than in elderly patients $(77 \%)$. The mean symptom to door time was $9 \pm 19$ hours in young patients and $12 \pm 28$ hours in old patients $(p=0.22)$. The maximum time from symptoms onset to presentation was 3 days in young patients compared to 7 days in the old patients.

Table 1 - Baseline demographic and clinical characteristics of patients younger and older than 45 years.

\begin{tabular}{|c|c|c|c|}
\hline Variable & $\begin{array}{c}\text { Younger than } 45 \\
\quad(n=197)\end{array}$ & $\begin{array}{l}45 \text { or older } \\
(n=205)\end{array}$ & $P$-value \\
\hline Age (years), mean \pm SD (range) & $40 \pm 4(26-45)$ & $55 \pm 7(46-95)$ & 0.001 \\
\hline \multicolumn{4}{|l|}{ Gender } \\
\hline Female & $5(2.5)$ & $6(3.0)$ & \multirow{2}{*}{0.81} \\
\hline Male & $192(97.5)$ & $199(97.0)$ & \\
\hline History of hypertension & $50(25.0)$ & $75(36.0)$ & 0.01 \\
\hline History of diabetes mellitus & $80(40.0)$ & $108(52.0)$ & 0.01 \\
\hline History of dyslipidemia & $31(16.0)$ & $49(24.0)$ & 0.04 \\
\hline Newly diagnosed dyslipidemia & $89(44.0)$ & $67(32.0)$ & 0.01 \\
\hline Total dyslipidemia & $120(60.0)$ & $116(56.0)$ & 0.4 \\
\hline Obesity & $15(7.0)$ & $39(19.0)$ & 0.001 \\
\hline Smoking & $107(52.0)$ & $91(35.0)$ & 0.001 \\
\hline Substance abuse & $6(3.0)$ & $1(0.5)$ & 0.06 \\
\hline Family history of AMI & $5(2.5)$ & $1(0.5)$ & 0.12 \\
\hline History of AMI & $12(6.0)$ & $25(12.0)$ & 0.03 \\
\hline History of CABG & 0 & $2(1.0)$ & 0.5 \\
\hline History of PCI & $10(5.0)$ & $16(8.0)$ & 0.27 \\
\hline History of stroke/TIA & 0 & $3(1.5)$ & 0.25 \\
\hline History of COPD & $2(1.0)$ & $4(2.0)$ & 0.69 \\
\hline History of CKD & $2(1.0)$ & $5(2.5)$ & 0.45 \\
\hline \multicolumn{4}{|c|}{$\begin{array}{l}\text { Values are presented as numbers and percentages (\%). CABG: coronary artery bypass } \\
\text { graft, CKD: chronic kidney disease, COPD: chronic obstructive pulmonary disease, PCI: } \\
\text { percutaneous coronary intervention, TIA: transient ischemic attack, STEMI: ST-segment } \\
\text { elevation myocardial infarction, AMI: acute myocardial infarction, SD: standard deviation }\end{array}$} \\
\hline
\end{tabular}


Table 2 - Clinical presentation and outcomes of patients younger and older than 45 years.

\begin{tabular}{|c|c|c|c|}
\hline Variable & Less than $45(\mathrm{n}=197)$ & 45 or more $(n=205)$ & $P$-value \\
\hline $\mathrm{HR} /$ min, mean $\pm \mathrm{SD}$ (range) & $88 \pm 19(43-173)$ & $88 \pm 20(40-180)$ & 0.62 \\
\hline $\mathrm{SBP}(\mathrm{mm} \mathrm{Hg})$, mean $\pm \mathrm{SD}$ (range) & $133 \pm 25(84-229)$ & $135 \pm 25(83-232)$ & 0.28 \\
\hline $\mathrm{DBP}(\mathrm{mm} \mathrm{Hg})$, mean \pm SD (range) & $86 \pm 17(45-143)$ & $86 \pm 16(39-130)$ & 0.89 \\
\hline $\mathrm{SPO}_{2}$, mean $\pm \mathrm{SD}$ (range) & $97 \% \pm 3(69-100)$ & $96 \% \pm 4(65-100)$ & 0.02 \\
\hline Atypical presentation & $1(0.50)$ & $2(0.97)$ & 0.58 \\
\hline Symptoms to door time, mean $\pm S D$ (range) & $9 \pm 19(0.5-168)$ & $12 \pm 28(0.5-240)$ & 0.22 \\
\hline \multicolumn{4}{|l|}{ Type } \\
\hline $\begin{array}{l}\text { STEMI } \\
\text { Late STEMI }\end{array}$ & $\begin{array}{l}159(81.0) \\
38(19.0)\end{array}$ & $\begin{array}{l}159(77.0) \\
46(23.0)\end{array}$ & 0.44 \\
\hline \multicolumn{4}{|l|}{ Time of incidence } \\
\hline $\begin{array}{l}00 \text { to } 06 \\
06 \text { to } 12 \\
12 \text { to } 18 \\
18 \text { to } 00\end{array}$ & $\begin{array}{l}40(20.0) \\
53(27.0) \\
57(29.0) \\
47(24.0)\end{array}$ & $\begin{array}{l}48(23.0) \\
64(31.0) \\
52(25.0) \\
41(20.0)\end{array}$ & 0.52 \\
\hline \multicolumn{4}{|l|}{ Arrest } \\
\hline $\begin{array}{l}\text { Pre-hospital } \\
\text { In-hospital }\end{array}$ & $\begin{array}{l}1(0.5) \\
4(2.0)\end{array}$ & $\begin{array}{l}1(0.5) \\
2(1.0)\end{array}$ & $\begin{array}{l}0.98 \\
0.38\end{array}$ \\
\hline \multicolumn{4}{|l|}{ Killip class } \\
\hline $\begin{array}{l}\text { I/ II } \\
\text { III /IV } \\
\text { Cardiogenic shock }\end{array}$ & $\begin{array}{c}193(97.0) \\
5(3.0) \\
4(2.0)\end{array}$ & $\begin{array}{c}183(90.0) \\
21(10.0) \\
6(3.0)\end{array}$ & $\begin{array}{c}0.002 \\
0.56\end{array}$ \\
\hline \multicolumn{4}{|l|}{ Arrhythmias } \\
\hline $\begin{array}{l}\text { AF } \\
\text { Other arrhythmias }\end{array}$ & $\begin{array}{l}3(1.5) \\
8(4.0)\end{array}$ & $\begin{array}{c}2(1.0) \\
10(5.0)\end{array}$ & $\begin{array}{l}0.62 \\
0.69\end{array}$ \\
\hline Anterior wall MI & $96(49.0)$ & $113(55.0)$ & \multirow{2}{*}{0.2} \\
\hline Non-anterior wall MI & $101(51.0)$ & $92(45.0)$ & \\
\hline \multicolumn{4}{|l|}{ Ejection fraction } \\
\hline $\begin{array}{l}<35 \% \\
>35 \%\end{array}$ & $\begin{array}{c}47(24.0) \\
150(76.0)\end{array}$ & $\begin{array}{c}62(30.0) \\
143(70.0)\end{array}$ & 0.15 \\
\hline Thrombolysis & $32(16.0)$ & $38(18.0)$ & 0.27 \\
\hline Invasive strategy & $130(66.0)$ & $106(52.0)$ & 0.004 \\
\hline CABG referral & $1(0.50)$ & $5(2.5)$ & 0.12 \\
\hline \multicolumn{4}{|l|}{ In-hospital MACE } \\
\hline $\begin{array}{l}\text { Death } \\
\text { Stroke (TIA) } \\
\text { AKI }\end{array}$ & $\begin{array}{l}3(1.5) \\
2(1.0) \\
1(0.5)\end{array}$ & $\begin{array}{l}6(2.9) \\
2(1.0) \\
4(2.0)\end{array}$ & $\begin{array}{l}0.49 \\
0.97 \\
0.19\end{array}$ \\
\hline $\begin{array}{l}\text { Values are presented as numbers and } \\
\text { diastolic blood pressure, HR: heart rate, } \\
\text { saturation, SD: standard }\end{array}$ & $\begin{array}{l}\text { tages (\%). AF: atrial fib } \\
\text { myocardial infarction, } \mathrm{S} \\
\text { tion, MACE: major ad }\end{array}$ & $\begin{array}{l}\text { ion, AKI: acute kidney } \\
\text { ystolic blood pressure, } \\
\text { cardiovascular events }\end{array}$ & $\begin{array}{l}\text {, DBP: } \\
\text { oxygen }\end{array}$ \\
\hline
\end{tabular}

The mean initial and peak white blood counts values were higher in the younger than in the older patients $\left(13.5 \times 103\right.$ cells $/ \mathrm{mm}^{3}$ vs. $12.4 \times 103$ cells/ $\mathrm{mm}^{3}, p=0.005$; and $14.2 \times 103$ cells $/ \mathrm{mm}^{3}$ vs. $13.1 \times 103$ cells $/ \mathrm{mm}^{3}, \quad p=0.006$ ) (Figure 1A). There was no significant difference between the mean neutrophil and lymphocytic counts when compared between the 2 age groups $\left(10.02 \times 103\right.$ cells $/ \mathrm{mm}^{3}$ vs. $9.28 \times 103$ cells/ $\mathrm{mm}^{3}, p=0.06$; and $2.71 \times 103$ cells $/ \mathrm{mm}^{3}$ vs. $2.61 \times 103$ cells $/ \mathrm{mm}^{3}, \quad p=0.4$ ) (Figure $1 \mathrm{~B} \& \mathrm{C}$ ). Hemoglobin levels were comparable between the 2 groups with no significant difference $(14.75 \mathrm{~g} / \mathrm{dL}$ vs. $14.57 \mathrm{~g} / \mathrm{dL}$, $p=0.1$ ) (Figure 1D). In contrast, the mean creatinine level at presentation was significantly higher among the older patients $(90.3 \mu \mathrm{mol} / \mathrm{L}$ vs. $111.2 \mu \mathrm{mol} / \mathrm{L}$, $p=0.004$ ) (Figure 1E). The peak creatine kinase (CK) (1557.2 U/L vs. $1194.4 \mathrm{U} / \mathrm{L}, p=0.02)$, CK-MB (169 $\mathrm{U} / \mathrm{L}$ vs. $149 \mathrm{U} / \mathrm{L}, p=0.01$ ), and troponin levels 60 $\mathrm{ng} / \mathrm{mL}$ vs. $48 \mathrm{ng} / \mathrm{mL}, p=0.1$ ) were higher in younger patients than in older patients (Figure 1F-H). Similarly, the mean low-density lipoprotein $(3.35 \mathrm{mmol} / \mathrm{L}$ vs. $3.09 \mathrm{mmol} / \mathrm{L}, p=0.1)$ and total cholesterol levels (4.9 
$\mathrm{mmol} / \mathrm{L}$ vs. $4.7 \mathrm{mmol} / \mathrm{L}, p=0.04)$ were higher in the younger age group (Figure $2 \mathrm{~A} \& \mathrm{~B}$ ). Other laboratory findings and the left ventricle ejection fraction did not show any significant differences between the 2 groups (Table 2).

An invasive strategy was more commonly employed in the younger group than in the older group (66\% vs. $52 \%)$. Thrombolysis was performed on $32(16.2 \%)$ young patients and $38(18 \%)$ on the elderly group (Table 2). Referral to CABG capable centers was more common among the older patients compared to younger patents ( 1 vs. $5, p=0.1$ ) (Table 2 ). Pulmonary edema (Killip III) and cardiogenic shock (Killip IV) were more common in the elderly (5 vs. 21 ; odds ratio, 4.43; 95\% confidence interval, 1.750-10.94z) (Table 2). Other complications, such as cardiac arrest occurring pre-hospitalization or during hospital admission; arrhythmias, including atrial fibrillation; and in-hospital MACE, including death, stroke, and acute kidney injury, did not show statistically significant differences between the 2 groups (Table 2). Hospital stays were significantly longer in the older group than in the younger group $(4 \pm 2$ vs. $5 \pm 2$ days, $p=0.02)$ (Figure 2C).
Discussion. In the present study, we analyzed the clinical profiles of adults younger than 45 years of age who presented with STEMI and compared them to those of older patients. We found that young patients were more frequently smokers and had high dyslipidemia prevalence. The pathophysiology of STEMI in young patients can be different from that in the older population. ${ }^{2}$ Although atherosclerosis and plaque rupture are the most common causes of STEMI, younger patients are more prone to having coronary spasms, coronary spontaneous dissection, and vasculitis as underlying factors for acute coronary artery blockage. Moreover, histopathological studies have shown that atherosclerotic plaques in the younger age group develop more quickly and contain more lipids with a relative lack of cellular scar tissue compared to plaques seen in older patients. ${ }^{19}$ These plaques are considered highly vulnerable and prone to rupture; thus, they are more likely to cause STEMI than chronic stable angina at a younger age. ${ }^{20}$ Indeed, in our analysis, the prevalence of dyslipidemia was high in younger patients (60\%). Forty-four percent of those patients did not report having a history of dyslipidemia or receiving
A

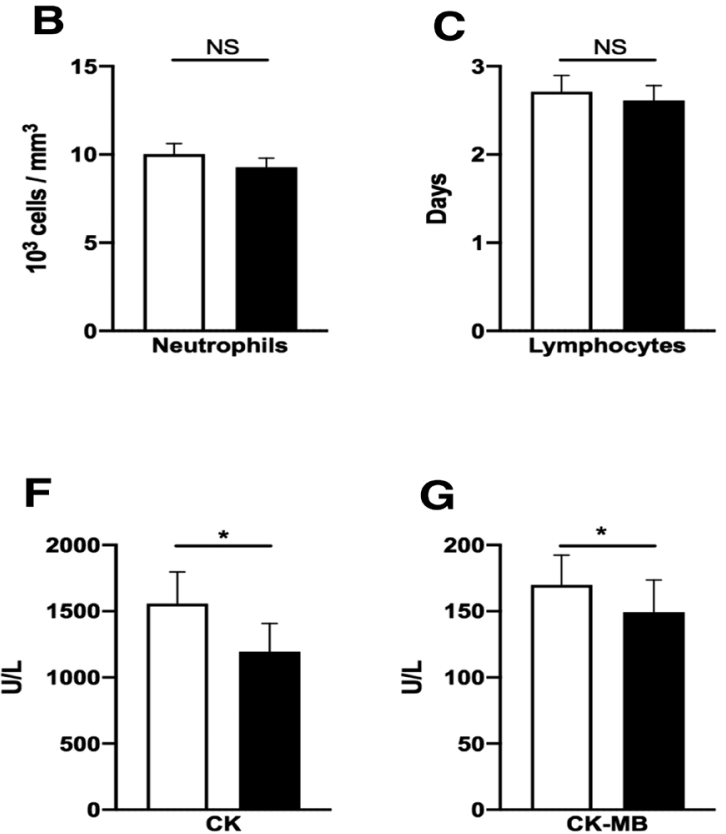

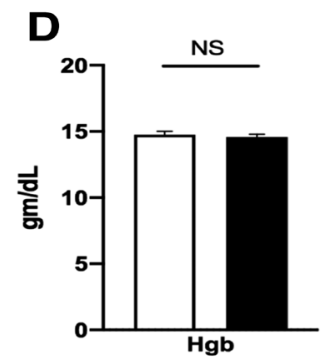

H

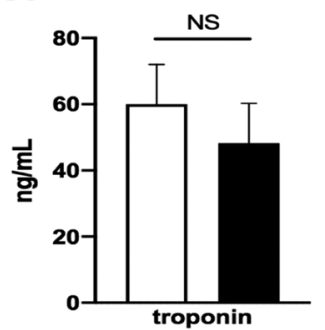

Figure 1 - Laboratory results for patients younger and older than 45 years. A) Mean white blood cell count (WBC) among patients younger than 45 years of age in comparison to that among patients aged 45 years or older at presentation. B-C) Mean neutrophil and lymphocytic count in patients younger and older than 45 years at presentation B) Mean hemoglobin (Hgb) level among patients younger than 45 years in comparison to that among patients aged 45 years or older. E) Mean creatinine level in patients younger than 45 years in comparison to that among patients aged 45 years or older. F-H) The cardiac markers creatine kinase (CK), creatine kinase-MB (CK-MB), and troponin among patients younger than 45 years in comparison to that among patients aged 45 years or older. ${ }^{*} p<0.05,{ }^{* *} p<0.01$, and error bars represent the $95 \%$ confidence interval. 

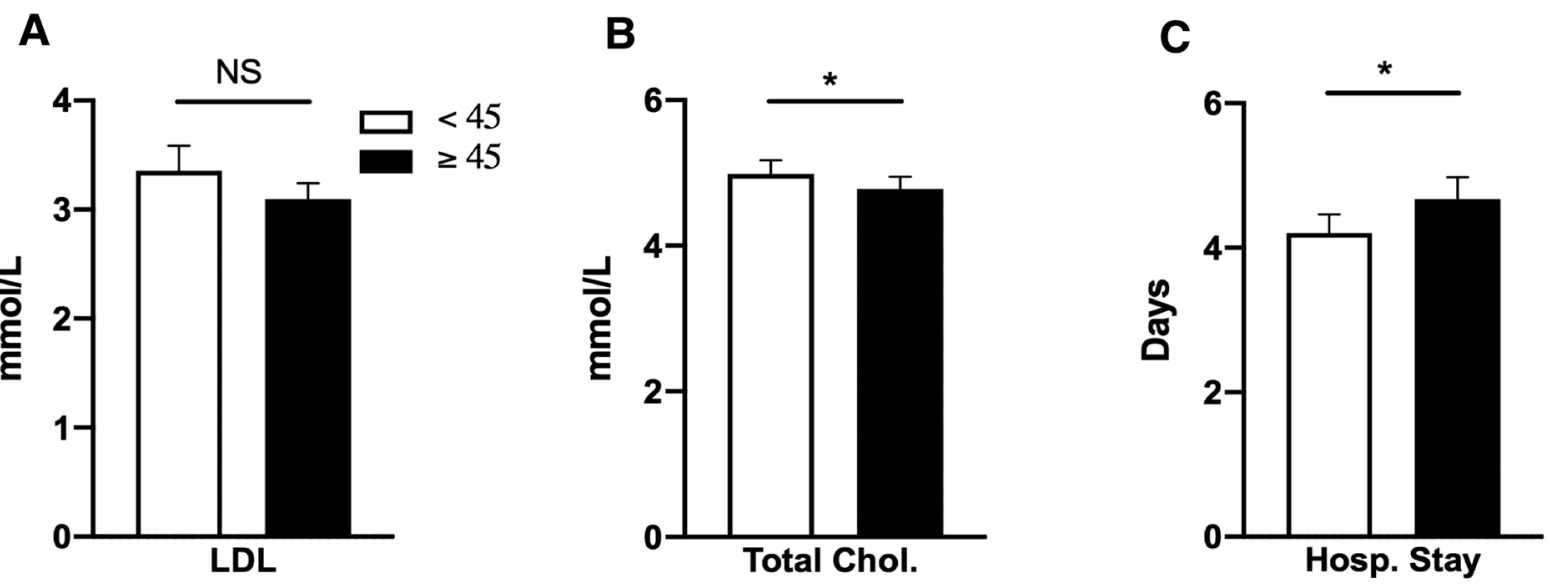

Figure 2 - Lipid profile and length of hospital stay for patients younger and older than 45 years. A-B) Mean low-density lipoprotein cholesterol (LDL) and total cholesterol in the two populations. C) Mean duration of hospital stay (in days) in patients younger and older than 45 years. ${ }^{*} p<0.05$, and error bars represent the $95 \%$ confidence interval. Hosp: hospital, Chol: cholesterol

any treatment, with only $16 \%$ being aware or receiving treatment. Although diabetes and hypertension were more prominent in the elderly, potentially due to aging and a higher prevalence of obesity, ${ }^{21}$ the dyslipidemia burden was similar between the 2 groups. Indeed, the immense burden of dyslipidemia among AMI patients has been reported locally and regionally. 22,23

Furthermore, coronary artery vasospasm complicating coronary atherosclerosis can lead to thrombus formation, which can cause AMI and even sudden cardiac death; however, spontaneous coronary reperfusion may occur in the early stages of myocardial infarction. ${ }^{24}$ Cigarette smoking is a major risk factor for both atherosclerosis and spasm, and endotheliummediated vasodilation has been found to be impaired in smokers. ${ }^{25}$ In the present study, we found that smoking was a prominent risk factor among young patients. Indeed, this is a well-documented risk factor for STEMI in youth, where several groups have reported smoking prevalence rates as high as 70\%-90\%, $1,26,27$ which is more than that reported in our study (52\%). In local epidemiological surveys, smoking is more prevalent among men (22\%) than women (1\%). ${ }^{16}$ This may explain in part the predominance of male STEMI patients $(97.5 \%)$ in our study. Furthermore, male gender is a major risk factor for STEMI, where female patients frequently present with non-STEMI or unstable angina. ${ }^{28,29}$ These findings shed light on the relationship between gender, smoking, and lipid profile in the early precipitation of STEMI. Several international guidelines have suggested early screening and treatment of dyslipidemia in patients as young as 25 years or younger, especially if they are smokers. ${ }^{30}$ The early introduction of statin therapy has resulted in a reduction in AMI rates. ${ }^{31}$

We observed a long symptom to door time in both age groups, which can be attributed to the inclusion of multiple late presenters (3-7 days). Although atypical presentation is frequently reported in older STEMI patients, we did not observe any difference between the 2 groups. ${ }^{32}$ However, the incidence of pulmonary edema and cardiogenic shock was approximately 3 -times higher in elderly patients (10\% vs. $3 \%)$. This can be attributed to the increased arterial stiffness, multiple comorbidities, and multi-vessel involvement that are usually found in the aforementioned group. ${ }^{33}$ Another related manifestation is the longer hospital stay observed in the same group, which can be attributed to the same reasons. In contrast, younger patients commonly present with single-vessel disease. ${ }^{34}$ The acute occlusion of a single vessel without established collaterals can explain the observed higher levels of CK, $\mathrm{CK}-\mathrm{MB}$, and troponin in young patients. With that, having a history of AMI and post-STEMI referral to $\mathrm{CABG}$ were less common among younger patients which further emphasize the difference in the extent of CAD between the 2 groups.

In our study, we discovered that $44 \%$ of young STEMI patients were unaware of their dyslipidemia status. The gap in their knowledge regarding the preexistence of such a condition is a potential driver of their premature presentation. ${ }^{35}$ Therefore, strict 
implementation of screening programs for dyslipidemia starting at a young age, especially for those at risk, such as smokers or those with a family history of AMI, is warranted. The age at which screening is initiated may differ from one region to another, along with local guidelines. ${ }^{36}$ Currently, the local guidance for dyslipidemia screening is focused on people aged 45 years or older. ${ }^{37}$ However, the youngest patient present with STEMI in our study was a 26-year-old man. Therefore, regional calls to establish and implement screening programs for dyslipidemia in young individuals are proliferating. ${ }^{35,38}$ On the same note, smoking remains an important modifiable risk factor for AMI in young individuals, and the high prevalence of this habit in the region has proven to be detrimental. Tackling both problems will require national coordinated efforts to establish screening guidelines as well as preventive task forces. Our work will serve as a regional and national reference for such diseases, along with its related comorbidities. Finally, we encourage further research on this topic and other related pathologies, such as stroke and renovascular diseases, in young patients to maximize our understanding and provide a basis for future regional guidance.

Study limitations. The present study was a singlecenter, retrospective case-control analysis. The data regarding newly-diagnosed diabetes and hypertension were missing for a number of patients, and thus were excluded from the analysis. Data regarding the number of vessels involved, number and type of stents deployed, cannot be retrieved for some patients also not included in the analysis. Furthermore, data on long-term all-cause mortality, re-hospitalization, recurrent AMI, stroke, and subsequent revascularization were not included since we lost follow up for large number of patients. Finally, our study design precludes the calculation of the prevalence and incidence of STEMI in young individuals, and our relatively small sample size may result in misjudgment of some analyses provided.

In conclusion, individuals younger than 45 years of age presenting with STEMI are predominantly smokers or having dyslipidemia. The majority of young patients with dyslipidemia are not aware of their pre-existing condition. In terms of outcome, younger patients are less likely to develop pulmonary edema and cardiogenic shock, and more likely to have a shorter length of hospital stay. Smoking prevention, adaptation, and implementation of a screening program for dyslipidemia with subsequent intervention for those at risk might decrease the burden of STEMI in young patients. Further regional studies on the burden and implications of AMI and dyslipidemia in young individuals are needed.
Acknowledgment. We thank Dr. Amal Aqqad, Dr. Ghayda Kullab, Dr. Ahmad Ramzy, and Mr. Saad Alsomali for their valuable contributions during the data collection process. We also would like to acknowledge Editage (www.editage.com) for English language editing.

\section{References}

1. Hoit BD, Gilpin EA, Henning H, Maisel AA, Dittrich H, Carlisle J, et al. Myocardial infarction in young patients: an analysis by age subsets. Circulation 1986; 74: 712-721.

2. Egred M, Viswanathan G, Davis GK. Myocardial infarction in young adults. Postgrad Med J 2005; 81:741-745.

3. Tuzcu EM, Kapadia SR, Tutar E, Ziada KM, Hobbs RE, McCarthy PM, et al. High prevalence of coronary atherosclerosis in asymptomatic teenagers and young adults: evidence from intravascular ultrasound. Circulation 2001; 103: 2705-2710.

4. Gaziano TA, Bitton A, Anand S, Abrahams-Gessel S, Murphy A. Growing epidemic of coronary heart disease in low- and middle-income countries. Curr Prob Cardiol 2010; 35: 72-115.

5. Gehani AA, Al-Hinai AT, Zubaid M, Almahmeed W, Hasani MR, Yusufali AH, et al. Association of risk factors with acute myocardial infarction in Middle Eastern countries: the INTERHEART Middle East study. Eur J Prev Cardiol 2014; 21: 400-410.

6. Yusuf S, Hawken S, Ounpuu S, Dans T, Avezum A, Lanas F, et al. Effect of potentially modifiable risk factors associated with myocardial infarction in 52 countries (the INTERHEART study): case-control study. Lancet 2004; 364: 937-952.

7. Fach A, Bünger S, Zabrocki R, Schmucker J, Conradi P, Garstka $\mathrm{D}$, et al. Comparison of outcomes of patients with ST-segment elevation myocardial infarction treated by primary percutaneous coronary intervention analyzed by age groups $(<75,75$ to 85 , and $>85$ Years); (Results from the Bremen STEMI registry). Am J Cardiol 2015; 116: 1802-1809.

8. Nadeem M, Ahmed SS, Mansoor S, Farooq S. Risk factors for coronary heart disease in patients below 45 years of age. PakJ Med Sci 2013; 29: 91-96.

9. Li S, Zhang HW, Guo YL, Wu NQ, Zhu CG, Zhao X, et al. Familial hypercholesterolemia in very young myocardial infarction. Sci Rep 2018; 8: 8861.

10. Zimmerman FH, Cameron A, Fisher LD, Ng G. Myocardial infarction in young adults: angiographic characterization, risk factors and prognosis (Coronary Artery Surgery Study Registry). J Am Coll Cardiol 1995; 26: 654-661.

11. General Authority for Statistics. Population in Riyadh region by gender, age group, and nationality (Saudi/Non-Saudi). [Updated 2017; 2021 March 12]. Available from: https://www. stats.gov.sa/en/5721

12. Saudi Arabia Labour Market, Fourth Quarter. [Updated 2017; 2021 March 12]. Available from: https://www.stats.gov.sa/ en/5718

13. Choudhury L, Marsh JD. Myocardial infarction in young patients. Am J Med 1999; 107: 254-261.

14. Shehab A, Bhagavathula AS, Alhabib KF, Ullah A, Suwaidi JA, Almahmeed W, et al. Age related sex differences in clinical presentation, management, and outcomes in ST-segment elevation myocardial infarction: Pooled analysis of patients from 7 arabian gulf registries. J Am Heart Assoc 2020; 9: e013880. 
15. Hosseini SK, Soleimani A, Karimi AA, Sadeghian S, Darabian S, Abbasi SH, et al. Clinical features, management and in-hospital outcome of ST elevation myocardial infarction (STEMI) in young adults under 40 years of age. Monaldi Arch Chest Dis 2009; 72: 71-76.

16. Moradi-Lakeh M, El Bcheraoui C, Tuffaha M, Daoud F, Al Saeedi M, Basulaiman M, et al. Tobacco consumption in the Kingdom of Saudi Arabia, 2013: findings from a national survey. BMC Public Health 2015;15: 611.

17. Al-Nozha MM, Al-Mazrou YY, Al-Maatouq MA, Arafah MR, Khalil MZ, Khan NB, et al. Obesity in Saudi Arabia. Saudi Med J 2005; 26: 824-829.

18. Naeem Z. Burden of Diabetes Mellitus in Saudi Arabia. Int J Health Sci (Qassim) 2015; 9: V-VI.

19. Osula S, Bell GM, Hornung RS. Acute myocardial infarction in young adults: causes and management. Postgrad Med J 2002; 78: 27-30.

20. Maseri A, Davies G, Hackett D, Kaski JC. Coronary artery spasm and vasoconstriction. The case for a distinction. Circulation 1990; 81: 1983-1991.

21. Zanella MT, Kohlmann O, Ribeiro AB. Treatment of obesity hypertension and diabetes syndrome. Hypertension 2001; 38: 705-708.

22. Ahmed AM, Hersi A, Mashhoud W, Arafah MR, Abreu PC, Al Rowaily MA, et al. Cardiovascular risk factors burden in Saudi Arabia: The Africa Middle East Cardiovascular Epidemiological (ACE) study. J Saudi Heart Assoc 2017; 29: 235-243.

23. Alsheikh-Ali AA, Omar MI, Raal FJ, Rashed W, Hamoui $\mathrm{O}$, Kane A, et al. Cardiovascular risk factor burden in Africa and the Middle East: the Africa Middle East Cardiovascular Epidemiological (ACE) study. PLoS One 2014; 9: e102830.

24. Williams MJ, Restieaux NJ, Low CJ. Myocardial infarction in young people with normal coronary arteries. Heart 1998; 79: 191-194.

25. Takaoka K, Yoshimura M, Ogawa H, Kugiyama K, Nakayama M, Shimasaki Y, et al. Comparison of the risk factors for coronary artery spasm with those for organic stenosis in a Japanese population: role of cigarette smoking. Int J Cardiol 2000; 72: 121-126.

26. Wolfe MW, Vacek JL. Myocardial infarction in the young. Angiographic features and risk factor analysis of patients with myocardial infarction at or before the age of 35 years. Chest 1988; 94: 926-30.

27. Jamil G, Jamil M, Alkhazraji H, Haque A, Chedid F, Balasubramanian $\mathrm{M}$, et al. Risk factor assessment of young patients with acute myocardial infarction. Am J Cardiovasc Dis 2013; 3: 170-174.
28. Yunyun W, Tong L, Yingwu L, Bojiang L, Yu W, Xiaomin H, et al. Analysis of risk factors of ST-segment elevation myocardial infarction in young patients. BMC Cardiovasc Disord 2014; 14: 179.

29. Hersi A, Al-Habib K, Al-Faleh H, Al-Nemer K, Alsaif S, Taraben A, et al. Gender inequality in the clinical outcomes of equally treated acute coronary syndrome patients in Saudi Arabia. Ann Saudi Med 2013; 33: 339-346.

30. Safeer RS, Ugalat PS. Cholesterol treatment guidelines update. Am Fam Physician 2002; 65: 871-880.

31. Silverman MG, Ference BA, Im K, Wiviott SD, Giugliano RP, Grundy SM, et al. Association between lowering LDL-C and cardiovascular risk reduction among different therapeutic interventions: A systematic review and meta-analysis. JAMA 2016; 316: 1289-1297.

32. Engberding N, Wenger NK. Acute coronary syndromes in the elderly. F1000Res 2017; 6: 1791.

33. Mehta RH, Rathore SS, Radford MJ, Wang Y, Wang Y, Krumholz HM. Acute myocardial infarction in the elderly: differences by age. J Am Coll Cardiol 2001; 38: 736-741.

34. Colkesen AY, Acil T, Demircan S, Sezgin AT, Muderrisoglu H. Coronary lesion type, location, and characteristics of acute ST elevation myocardial infarction in young adults under 35 years of age. Coron Artery Dis 2008; 19: 345-347.

35. Alasnag M, Awan Z, Al Ghamdi A, Al Modaimeigh H, Al Shemiri M. Improvement initiative in LDL-C management in Saudi Arabia: A call to action. Int J Cardiol Heart Vasc 2020; 31: 100667.

36. Ballantyne C, Arroll B, Shepherd J. Lipids and CVD management: towards a global consensus. Eur Heart J 2005; 26: 2224-2231.

37. Ministry of Health. Saudi Cardiometabolic Risk Management Guidelines in Primary Care. [Updated 2013; 2021 March 18]. Available from: https://www.moh.gov.sa/Ministry/About/ Health\%20Policies/026.pdf

38. AlQuaiz AM, Kazi A, Alodhayani AA, Almeneessier A, AlHabeeb KM, Siddiqui AR. Age and gender differences in the prevalence of chronic diseases and atherosclerotic cardiovascular disease risk scores in adults in Riyadh city, Saudi Arabia. Saudi Med J 2021; 42: 526-536. 